\title{
Beta blockade in essential hypertension: an analysis of response to oxprenolol
}

\author{
D. W. BARRITT AND A. J. MARSHALL
}

From the Bristol Royal Infirmary

The data from 40 patients with essential hypertension treated with oxprenolol alone have been used to analyse the falls of blood pressure and heart rate. Blood pressure and heart rate did not fall further as the daily dose was increased above $160 \mathrm{mg}$. The range of fall in mean pressure was from 0 to $40 \mathrm{mmHg}$ and there was no clear separation into response groups. Pressure falls were unrelated to sex, age, initial heart rate, increase in heart rate on standing, the fall of heart rate with the drug, or the initial height of blood pressure. In the absence of predicting factors the use of oxprenolol, and, by deduction, other beta blocking agents, in hypertension remains empirical, but the simplification of the dose range allows the response to oxprenolol to be determined quickly.

All beta blocking drugs which have been tested in hypertension have been shown to have a hypotensive effect. In two trials propranolol, practolol, oxprenolol, metoprolol, timolol, pindolol, alprenolol, and tolamolol were found to be effective hypotensive agents (Morgan et al., 1974; Davidson et al., 1976), and it appears to be the case that the possession of attributes such as cardioselectivity, intrinisic sympathomimetic activity, and membrane stabilising activity are irrelevant in this respect.

Several important aspects of the use of beta blockade await clear definition. For instance, there is dispute about the dose range to be employed with the most used agents, propranolol and oxprenolol. Dose ranges for propranolol have been quoted from 10 to $4000 \mathrm{mg}$ daily (Prichard and Gillam, 1969), whereas in a recent study no benefit from doubling the dose from 120 to $240 \mathrm{mg}$ daily was found (Galloway et al., 1976). Our initial studies with oxprenolol (Marshall and Barritt, 1973; Barritt et al., 1976) adopted a dose range from 160 to $1280 \mathrm{mg}$ daily, but analysis of the dose response suggested that there was no demonstrable benefit from higher dosage. The dose range must obviously be matched against the magnitude of pressure fall and exact assessment of the range of pressure fall at all levels of severity of hypertension will be an important guide to the value of the agent. In the same way the proportion of patients who will show little or no response should be ascertained. All clinicians would welcome any simple clinical

Received for publication 4 November 1976 analysis likely to preduct a patient's response to beta blockade.

This paper attempts to answer these questions for oxprenolol.

\section{Patients and methods}

Forty patients with essential hypertension were studied. The mean systolic blood pressure was $175 \mathrm{SD} \pm 20$ and diastolic $111 \mathrm{SD} \pm 9 \mathrm{mmHg}$. The trials in which they took part have previously been reported (Marshall and Barritt, 1973; Barritt et al., 1976). Seventeen were men, and 23 were women, and their age range was from 30 to 73 years. Renal disease was excluded by examining the abdomen, testing the urine for albumin, and measuring blood urea and electrolytes. Endocrine hypertension was excluded by clinical examination and measurement of urinary catecholamine excretion. The presence of obstructive airways disease, cardiac failure, or hypertensive complications requiring immediate treatment, were reasons for exclusion. All the patients were new hypertensives who had received no previous treatment, and received no other hypotensive agent during the period of study.

After the initial assessment they attended a clinic specially set aside for the study. Every patient attended this clinic on 4 occasions at weekly intervals before starting treatment. Each patient was seen throughout by the same physician and the blood pressure was measured blindly using the London School of Hygiene and Tropical Medicine sphygmomanometer. Blood pressure was measured after 5 
minutes' rest in the supine position, after standing for 2 minutes, and then after 1 minute of two-step exercise. Heart rate was also recorded. The starting dose of oxprenolol was always $80 \mathrm{mg}$ twice daily. If the blood pressure did not fall to near normal levels, the dose was doubled at 2-weekly intervals, to a maximum of $1280 \mathrm{mg}$ daily. The effect of treatment was assessed on three attendances at monthly intervals, when the patient was taking the maximum dose.

Statistical analysis was by correlation coefficient and Student's t test. Mean blood pressure has been calculated as follows:

$\underline{\text { Systolic pressure }+ \text { diastolic pressure } \times 2}$ 3

In this paper, the term mean pressure always applies to this calculation.

\section{Results}

\section{DOSE EFFECT}

Neither trial whose results are further analysed in this paper was designed primarily to study dose response. In both it was assumed that if pressure fall at low dosage was inadequate, the correct step was to increase the dosage.

The final pressure fall (supine) has been related to the highest daily dose used in each of the 40 patients (160 to $1280 \mathrm{mg}$ ). This gives a correlation coefficient of -0.334 , standard error $0 \cdot 164$. An individual analysis of pressure fall against dosage has been made in 14 patients who were given between 480 and $960 \mathrm{mg}$ daily. The effect of increasing dosage was unpredictable. Pressure fall was plotted against the dose and the slope of the line tested for significance against zero. One patient only showed a statistically significant fall in systolic pressure, as the dose was increased, but two others showed a significant rise in diastolic pressure. Heart rates were analysed similarly. No patient showed a significant fall in heart rate with increased dosage, but one showed a significant rise. Percentage falls in mean blood pressure have been calculated for each of the 40 patients. Seven achieved falls of 25 per cent or more and each of these 7 were taking $160 \mathrm{mg}$ daily.

Thus, there are no grounds for expecting that increasing the daily dose above 160 or $320 \mathrm{mg}$ will lead to any further fall of pressure.

\section{BLOOD PRESSURE FALLS RELATED TO}

INITIAL PRESSURES

The falls in mean blood pressure (supine) have been related to initial mean pressures. Correlation coefficient is $0 \cdot 148$, standard error $0 \cdot 160$. Thus the initial height of the blood pressure in hypertensive patients does not affect the amount of pressure fall with this drug.

\section{PROPORTION OF GOOD AND POOR RESPONDERS}

Actual falls in mean blood pressure (supine) range from -2 to $40 \mathrm{mmHg}$. Nine patients had falls from -2 to $+9 \mathrm{~mm}, 11$ from 10 to $19 \mathrm{~mm}, 11$ from 20 to $29 \mathrm{~mm}$, and 9 from 30 to $40 \mathrm{~mm}$. Thus this population of 40 hypertensive patients cannot be divided into 'responders' and 'non-responders'. There is a steady progression of effectiveness in producing falls in mean blood pressure from 0 to 32 per cent. The greatest fall in average systolic pressure in any patient was from 189 to $127 \mathrm{mmHg}$ and the greatest fall in diastolic pressure from 116 to 74 $\mathrm{mmHg}$.

\section{EFFECT OF OXPRENOLOL ON HEART RATES}

The fall in supine heart rate was calculated at all dose levels. Fourteen patients were maintained on $160 \mathrm{mg}$ daily, and $13 \mathrm{on} 960 \mathrm{mg}$ or $1280 \mathrm{mg}$ daily. This allowed us to make many observations over a period of weeks at the same dose level. The mean fall in heart rate at $160 \mathrm{mg}$ was 13 beats $/ \mathrm{min}$ $(\mathrm{SD} \pm 8)$ and at $960 \mathrm{mg}$ or over it was $12(\mathrm{SD} \pm 8)$. Similarly the mean fall in post-exercise heart rate at $160 \mathrm{mg}$ daily was 24 beats $/ \mathrm{min}(S D \pm 11)$, at $960 \mathrm{mg}$ or over it was 21 (SD \pm 10$)$. Each of these four differences was statistically significant compared with pretreatment values $(\mathbf{P}<0.001)$. Patients in the intermediate dose range showed similar falls in heart rate. It is the case, therefore, that we failed to show any further fall in heart rate if the dose were increased above $160 \mathrm{mg}$ daily.

These falls in supine and post-exercise heart rate were correlated with falls in blood pressure. The correlation coefficients were 0.089 , standard error $0 \cdot 160$, and $0 \cdot 292$, standard error $0 \cdot 169$, respectively. We were, therefore, unable to show a relation between the fall in heart rate with oxprenolol and its hypotensive action.

\section{PREDICTING LIKELY RESPONSE TO}

\section{OXPRENOLOL}

\section{(1) $\operatorname{Sex}$}

In this population sex did not help to predict the fall in blood pressure.

\section{(2) Age}

Age was related to pressure fall. The correlation coefficient was 0.071 , standard error $0 \cdot 160$. Thus pressure falls were as great in the old as the young. (3) Initial heart rate

Supine heart rates in the pretreatment period have been correlated with the hypotensive response. 
The correlation coefficient was $-0 \cdot 214$, standard error $0 \cdot 160$. There was thus no tendency for those with higher initial heart rates to have a greater fall in blood pressure.

\section{(4) Changes in heart rate with change in posture from supine to erect}

Changes in heart rate on standing were correlated with the hypotensive response. The correlation coefficient was $0 \cdot 300$, standard error $0 \cdot 160$. There was thus a weak tendency for those patients whose heart rate increased on standing to have a greater fall in blood pressure with beta blockade.

\section{(5) Does the height of pretreatment blood pressure affect size of fall with treatment?}

This point has been covered in the previous section, and the result is clearly negative.

\section{Discussion}

Observations of blood pressure level and heart rates are easily distorted by the circumstances in which they are made. Throughout these studies every effort has been made to minimise observer error and the disturbing effect of attending a hospital clinic. We emphasise that 5 pretreatment observations were made, of which the first was discarded, at least three measurements were made at the final dose level, all blood pressure measurements were taken blindly by only two observers to whom the patients became well known. The clinic routine was unhurried, but there was virtually no waiting period and all of the observations were made at the same time of day. No patient included in this study received any other hypotensive medication.

Our analysis of the dose range used in these studies leads us to conclude that nothing useful is gained by increasing the daily dose above 160 or $320 \mathrm{mg}$. In planning the study we followed the convention that if the blood pressure did not fall near to normal levels at the starting dose of $80 \mathrm{mg}$ twice daily, the dose would be increased up to seven times. The negative correlation -0.334 between the size of the dose and the fall in blood pressure achieved has to be explained. We favour the following explanation. Firstly, we do not think that increasing dosage above $160 \mathrm{mg}$ daily is effective in lowering pressure further. Secondly, the design of the trial resulted in higher doses for those with poorer falls in pressure. Thus, those with the least fall in pressure were given the highest doses. We do not have sufficiently detailed evidence of any possible difference in dose response between 160 and $320 \mathrm{mg}$ daily to make a recommendation as to which of the two doses should routinely be regarded as maximal.
We have failed to show that increasing the daily dosage had any effect on the blood pressure. Equally there are significant falls in supine and post-exercise heart rates at $160 \mathrm{mg}$ daily but no further fall even though the dose be increased six times. The technique used in these studies was to count heart rates immediately after stopping a 1minute two-step exercise. In these patients this produced in the pretreatment period heart rates in the range 90 to 140 beats per minute. The fall in heart rate with treatment allows us to conclude that with doses of $80 \mathrm{mg}$ twice daily a high degree of beta blockade exists. Our recommendation is that if doses higher than $320 \mathrm{mg}$ daily are given, they should only be continued if there is well-substantiated evidence in that patient that the higher dose has reduced blood pressure consistently.

Our attempt to find clinical features that might predict the patient's response to beta blockade has produced only negative answers. Neither sex nor age appears to be relevant. It might be supposed that response to beta blockade would be especially good in those patients with high levels of sympathetic activity. For this reason we have analysed resting and post-exercise heart rates together with the increase in heart rate on assuming the erect posture. No significant correlation has emerged when each of these measurements is related to blood pressure fall. Nor does the height of pretreatment blood pressure influence how much pressure will fall.

Mean blood pressure can be expected to fall by as much as 32 per cent in some patients. The potency of oxprenolol corresponds very closely to that of methyldopa (Barritt et al., 1976).

There is no satisfactory explanation as to how beta blockade lowers blood pressure. If the suppression of cardiac output were the principal mode of action we would expect that there would be a clear relation between the fall in heart rate and the fall in blood pressure. The absence of any such close relation suggests to us that this is not of crucial importance.

In these studies no measurements of plasma renin have been made. Clearly the clinician prefers to observe the blood pressure fall with $160 \mathrm{mg}$ daily rather than speculate on the possible response from the level of plasma renin.

Reference has already been made to the level of sympathetic tone and its suppression with this beta blocking agent. Again the evidence is against this being of prime importance.

\section{Conclusion}

Beta blockade may be effective in any patient with essential hypertension. If oxprenolol is used there is 
little to be gained by increasing the daily dose above $320 \mathrm{mg}$. If the level of pretreatment blood pressure exceeds $200 / 115 \mathrm{mmHg}$ there is little chance that, with this agent alone, pressure will fall to the normal range.

\section{References}

Barritt, D. W., Marshall, A. J., and Heaton, S. (1976). Comparison of oxprenolol and methyldopa in hypertension. A within-patient double-blind trial. Lancet, 1, 503-505.

Davidson, C., Thadani, U., Singleton, W., and Taylor, S. H. (1976). Comparison of antihypertensive activity of beta blocking drugs during chronic treatment. British Medical fournal, 2, 7-9.

Galloway, D. B., Glover, S. C., Henıdy, W. G., Logie, A. W.,
Petrie, J. C., Smith, M. C., Lewis, J. A., and Simpson, W. T. (1976). Propranolol in hypertension: a dose-response study. British Medical fournal, 2, 140-142.

Marshall, A. J., and Barritt, D. W. (1973). Oxprenolol in hypertension. British fournal of Clinical Practice, 27, 337-340.

Morgan, T. O., Sabto, J., Anavekar, S. N., Louis, W. J., and Doyle, A. E. (1974). A comparison of beta adrenergic blocking drugs in the treatment of hypertension. Postgraduate Medical fournal, 50, 253-259.

Prichard, B. N. C., and Gillam, P. M. S. (1969). Treatment of hypertension with propranolol. British Medical fournal, 1, 7-16.

Requests for reprints to Dr. D. W. Barritt, Bristol Royal Infirmary, Bristol BS2 8HW. 